\title{
Central retinal artery occlusion in patient with microscopic polyangiitis
}

\author{
Oclusão da artéria central da retina em \\ paciente com poliangeíte microscópica
}

Cláudia Gallicchio Domingues', Chrissiê Fianco Capitanio², Luciana Boff de Abreu³, Marcus Vinícius Mattana ${ }^{4}$

\begin{abstract}
The microscopic polyangiitis is a systemic necrotizing vasculitis that affects arterioles, capillaries and venules, but can also reach small and medium-sized arteries. It is considered a rare disease, idiopathic in nature but clearly autoimmune. Several ocular and systemic abnormalities are associated with retinal arterial occlusions. Among the collagen vascular diseases, the literature cited as possible causes of retinal artery obstruction lupus erythematosus, polyarteritis nodosa, giant cell arteritis, Wegener's granulomatosis and lymphoid Liebow. Until now, there were no reports in the literature of the association of cases of arterial occlusion retinana associated with PAM. The authors report a case of a 53 years old patient diagnosed with microscopic polyangiitis who presented with important renal artery occlusion and associated unilateral central retinal artery occlusion. An extended systemic evaluation of patients presenting with central retinal artery occlusion should include research of PAM through analysis op p-ANCA.

Keywords: Retina/pathology; Retinal vasculitis/diagnosis;Anti-neutrophil cytoplasmic antibody-associated vasculitis/complications; Central retinal artery occlusion/etiology; Ophthalmologic emergency/therapy; Case reports
\end{abstract}

\section{ResUMO}

A poliangeíte microscópica é uma vasculite necrotizante sistêmica que acomete arteríolas, capilares e vênulas, mas também pode atingir pequenas e médias artérias. É considerada uma doença rara, idiopática e autoimune. Diversas anormalidades oculares e sistêmicas estão associadas às oclusões arteriais retinianas. Dentre as doenças vasculares do colágeno, a literatura cita como possíveis causas de obstrução das artérias retinianas o lúpus eritematoso sistêmico, a poliarterite nodosa, a arterite de células gigantes, a granulomatose de Wegener e a granulomatose linfóide de Liebow. Até o presente momento, não se encontrou na literatura relatos da associação de casos de oclusão arterial retinana associados à PAM. Os autores relatam o caso de um paciente com poliangeíte microscópica que apresentou comprometimento renal importante e oclusão da artéria central da retina unilateral. Atenta-se para a inclusão de pesquisa da PAM, através do p-ANCA, na avaliação de possível origem sistêmica em pacientes acometidos por oclusão arterial retiniana.

Descritores: Retina/patologia; Vasculite retiniana/diagnóstico; Vasculite associada a anticorpo anticitoplasma de neutrófilos/ complicações; Oclusão de artéria central da retina/etiologia; Emergência oftalmológica/terapia; Relatos de casos

\footnotetext{
${ }^{1,4}$ Hospital Geral de Caxias do Sul, Universidade de Caxias do Sul - Caxias do Sul (RS), Brasil.

${ }^{2}$ Clínica Médica da Associação Farroupilhense Pró-Saúde - Farroupilha, (RS), Brasil;

3 Pontifícia Universidade Católica do Rio Grande do Sul - Porto Alegre (RS), Brasil;

Study conducted at the General Hospital of Caxias do Sul, University of Caxias do Sul, Caxias do Sul, RS, Brazil.

The authors declare no conflicts of interests.

Recived for publication 27/03/2013 - Accepted for publication 03/02/2014
} 


\section{INTRODUCTION}

$\mathbf{M}$ icroscopic polyangiitis (MPA) is a systemic, rare, idiopathic necrotizing vasculitis, but with a clearly autoimmune nature, affecting approximately 1:100,000 people ${ }^{(1-3)}$. Symptoms usually begin around 50 to 60 years old, although individuals of any age can be affected. MPA is usually manifested with constitutional symptoms, such as weight loss, fever, myalgia and polyarthralgia, palpable purpura (skin vasculitis) and reno-pulmonary syndrome ${ }^{(4-6)}$. MPA is associated to the antineutrophil cytoplasmic antibodies (ANCA), where there is the predominance of the standard p-ANCA, though cANCA may also be found ${ }^{(1)}$.

The central retinal artery occlusion (CRAO) is an ophthalmic emergency characterized in general by the presence of acute, devastating and unrecoverable sight loss. Experimental studies in Rhesus monkeys have shown that after 240 minutes of ischemia the retinal tissue typically presents a massive and irreversible damage ${ }^{(7)}$. The treatments are based on the attempt to restore quickly the retinal blood flow. In ophthalmic practice, patients usually come to the appointment after that period. In most cases, therefore, blindness appears due to the lack of timely treatment for the recovery of sight. In other cases, there is permanent visual loss because there is no reestablishment of the retinal flow with any of the treatments available (sudden decompression of the eyeball, fibrinolytics, etc.). Once most cases of CRAO causes severe and irreversible visual loss, it is essential to determine the etiology of the disease, seeking prevention of impairment of the contralateral eye $\mathrm{e}^{(7-10)}$.

Several and systemic ocular abnormalities are linked to retinal arterial occlusions. Among the collagen vascular disease, literature mentions as possible causes of obstruction of the retinal arteries systemic erythematosus lupus, polyarteritis nodosa, giant cell arteritis, Wegener's granulomatosis and Liebow's lymphomatoid granulomatosis ${ }^{(8,10)}$.

At the moment it is not found in the literature reports of MPA associated to cases of retinana arterial occlusion. The authors report the case of a 53-year-old patient with microscopic polyangiitis which presented significant renal impairment and central artery occlusion of the unilateral retina.

\section{Case Report}

D.F.S, 53 years old, male, black, construction worker, native of Vacaria and from Caxias do Sul, sought medical attention with a history of sudden low visual acuity in the right eye accompanied by headache, paresis, paraesthesia and edema in upper and lower limbs for 20 days. In the last 3 months had non-productive cough, dyspnoea, loss of approximately $18 \mathrm{Kg}$, episodes of fever of about $38^{\circ} \mathrm{C}$, myalgia and polyarthralgia. In the psycho-social profile, the patient reported being a strong ex-smoker and ex-alcoholic for about 1 year. There was no previous medical history of systemic hypertension treated by hydrochlorothiazide and enalapril.

On hospitalization complementary exams showed: hematocrit equals to $26.9 \%$, hemoglobin equals to $8.8 \mathrm{~g} / \mathrm{dL}$, creatinine equals to $5.5 \mathrm{mg} / \mathrm{dL}$, urea equals to $152 \mathrm{mg} / \mathrm{dL}$, proteinuria of 24 hours equals to $233.4 \mathrm{mg}$, HSS equals to 157 $\mathrm{mm} / \mathrm{h}$ and C-reactive protein equals to $48 \mathrm{~g} / \mathrm{mL}$. The protein electrophoresis revealed polyclonal increase in the region of gamma globulins. Examination of the cerebrospinal fluid obtained by lumbar puncture showed no changes. The rheumatoid factor (RF), antinuclear antibody (FAN), VDRL and anticardiolipin antibody were negative. The ANCA research was positive and revealed a perinuclear pattern ( $\mathrm{p}$-ANCA) by indirect immunofluorescence.

Kidney ultrasound showed no changes. Chest computed tomography (CT) showed diffuse infiltration with interstitial and acinar components, with distribution throughout the bronchovascular beams bilaterally with predominance in the right hemithorax, center lobar emphysema, opacities on the basis of the right hemithorax. CT and magnetic resonance imaging (MRI) of the skull showed absence of signs consistent with ischemic stroke. Histopathology of right temporal artery revealed areas of inflammation and necrosis (absence of granulomas). During hospitalization, there was worsening of symptoms. The patient evolved with non-oliguric and non-dialytic acute renal failure.

The patient referred having suffered sudden loss of sight in his right eye, and an ophthalmologic evaluation was scheduled in the central ambulatory 9 days after his hospitalization. The eye exam revealed visual acuity of vision of figures on the right eye and 20/20 on the left eye. The intraocular pressure was equal to $12 \mathrm{mmHg}$ on right eye (RE) and the $11 \mathrm{mmHg}$ on left eye (LE). Biomicroscopic examination revealed no changes in both eyes.

Fundus examination of the RE showed diffuse retinal whitening, sparing the macular region (cherry red spot in the macula), being the condition compatible with central artery occlusion of the retina. There were no abnormalities in the fundus examination of the LE. Retinography and fluorescein angiography were requested and were made about 25 days after the initial fundus examination. The retinography (Figure 1) also showed a discreet (in resolution) diffuse retinal paleness with a cherry red spot in the macula on the RE. The retinography of the LE showed a small area of superficial intra-retinal haemorrhage with white center in the lower temporal arch. Therefore, the retinography findings confirmed and documented the diagnosis of the central retinal artery occlusion on the RE. The patient was talked about the absence of specific treatment for the RE. The treatment of underlying disease (systemic vasculitis) was requested and a return was suggested 7 days later for eye follow-up, including the LE.

At the time of the eye evaluation, the team at ophthalmologic clinic had as a diagnostic hypothesis systemic vasculitis, including the possibility of MPA or Wegener's granulomatosis. Laboratory exams had already been requested, including p-ANCA and c-ANCA, as well as a biopsy of the temporal artery had been performed.

Once the diagnosis of MPA was confirmed, a monthly pulse therapy was established with methylprednisolone $500 \mathrm{mg}$ at a dose of $1 \mathrm{~g}$ IV daily for 3 days. On the fourth day cyclophosphamide $1 \mathrm{~g}$ at a dose of $750 \mathrm{mg} / \mathrm{m}^{2}$ was administered. During the intervals of pulse therapy, prednisone $20 \mathrm{mg}$ was prescribed at a dose of $60 \mathrm{mg}$ per day, associated to azathioprine $50 \mathrm{mg}$ at a dose of $100 \mathrm{mg}$ per day. Six monthly cycles were held this pulse therapy scheme. After 45 days since the beginning of the treatment, the patient evolved with improvement of the kidney function and decrease of inflammatory markers.

On hospital discharge, a systemic immunosuppressant (azathioprine $50 \mathrm{mg}$ at a dose of $100 \mathrm{mg}$ per day) and an oral corticosteroids (prednisone $20 \mathrm{mg}$ at a dose of $40 \mathrm{mg}$ per day) were prescribed. The patient was referred to the rheumatology and ophthalmology ambulatory for a follow-up. 
The eye examination carried out a year after the episode of CRAO revealed visual acuity of vision of figures on the RE and 20/20 on the LE. The intraocular pressure was equals to $12 \mathrm{mmHg}$ on the RE and $11 \mathrm{mmHg}$ on the LE. Biomicroscopic examination revealed no changes in both eyes. The fundus examination of the RE showed generalized vascular narrowing and optic nerve pallor. There were no abnormalities in the fundus examination of the LE. A retinography was made for documentation. (Figure 2).

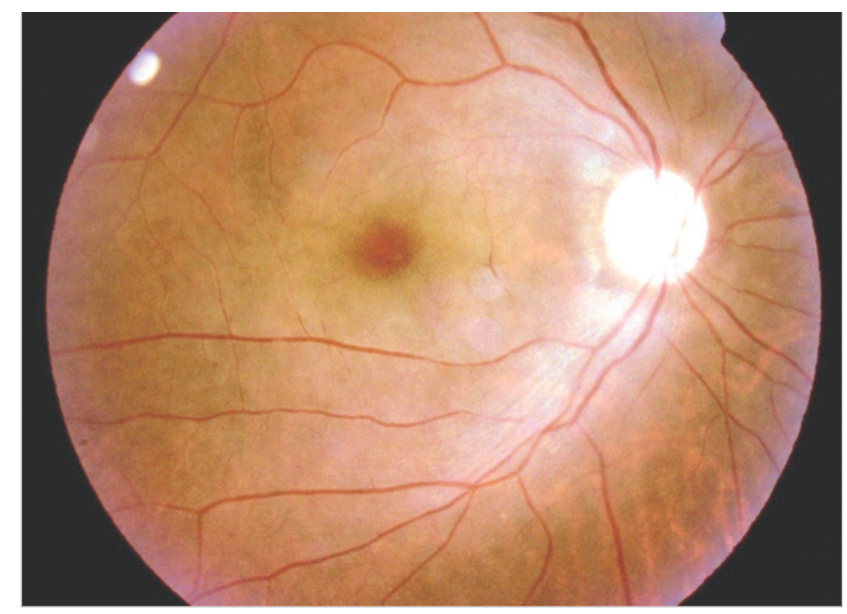

Figure 1. Retinography of the right eye with discreet diffuse retinal pallor (in resolution) cherry red spot in the macula.

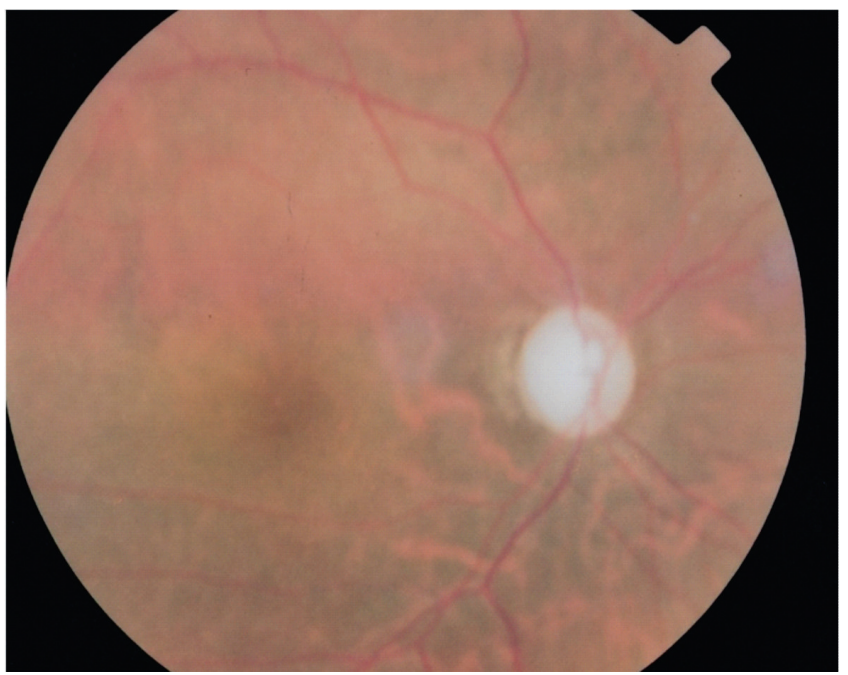

Figure 2. Retinography of the right eye with generalized vascular narrowing and optic nerve pallor.

A year after the diagnosis, the patient keeps using a systemic immunosuppressant (azathioprine $50 \mathrm{mg}$ at a dose of $100 \mathrm{mg}$ per day) and oral corticosteroids (prednisone $20 \mathrm{mg}$ at a dose of $10 \mathrm{mg}$ per day), with no recurrences of the disease.

\section{DisCUSSION}

MPA is an autoimmune necrotizing vasculitis of the microvasculature (capillaries, venules and arterioles), and more rarely can affect small and medium-sized arteries. It is characterized by the absence or scarcity of vascular immune deposits in direct immunofluorescence, being associated to antineutrophil cytoplasmic antibodies (ANCA), where there is the predominance of the p-ANCA pattern, although c-ANCA may also be found ${ }^{(1)}$. There is a relationship between men and women of 1:2 and onset of symptoms around 50 to 60 years, although individuals of any age may be affected ${ }^{(1-3)}$.

MPA usually manifests with constitutional symptoms, such as weight loss, fever and myalgia. Other findings include polyarthralgia, cutaneous vasculitis (palpable purpura) and renopulmonary syndrome. Joint and muscle complaints can precede the emergence of kidney and/or lung changes. Kidney impairment occurs in about $80 \%$ of cases, with focal glomerulitis and segmental necrotizing being observed, manifesting with microscopic hematuria, nephritic or nephrotic syndrome, and may even reach the dialysis kidney failure. Lung impairment is less common, occurring in about $12 \%$ of cases, and may manifest with cough, dyspnea, chest pain and hemoptysis (alveolar hemorrhage) due to pulmonary capillaritis. The radiological image can highlight opacity or alveolar infiltrate ${ }^{(4-6)}$.

The occlusion of the central retinal artery manifests with sudden loss of sight. The diagnosis is essentially clinical, showing pale retinal edema which saves the macular region that shows a typical cherry red spot in the macula stain. Fluorescein angiography confirms the clinical suspicion, showing a delayed retinal blood circulation. Subsequently, the milky appearance of the retina disappears within 2 to 6 weeks, and an optic atrophy may occur ${ }^{(7,8)}$.

In this case, the patient presented constitutional symptoms, sudden loss of sight on the right eye (central retinal artery occlusion), peripheral neuropathy, pulmonary manifestations, non-oliguric acute kidney failure, increased inflammatory markers and normochromic normocytic anemia (anemia of chronic disease).

ANCA are autoantibodies having specificity for cytoplasmic constituents of monocytes and neutrophils, and are serum markers used in the diagnosis and monitoring of small vessel vasculitis. Microscopic polyangiitis belongs to the spectrum of vasculitis associated to ANCA, usually causing a perinuclear staining pattern in the immunofluorescence examination ( $p$ ANCA). Besides the detection of antibodies in MPA, a lung and/ or kidney biopsy is necessary depending on the patient's condition $^{(1,6)}$. The ANCA research for the patient above was positive and revealed a perinuclear pattern ( $\mathrm{p}-\mathrm{ANCA}$ ) by indirect immunofluorescence.

The MPA must be differentiated from Wegener's granulomatosis (WG) and the Churg-Strauss syndrome (CSS), which are also autoimmune vasculitis of small vessels associated to antineutrophil cytoplasmic antibodies (ANCA) and with similar histological features. Any type of ANCA can be seen in those vasculitis; however, the c-ANCA pattern is predominant in WG and p-ANCA in CSS. The differential diagnosis between MPA and WG is made with the histopathological examination: in the first disease granulomas are not observed; in the second, this change is almost always visible (skin, lung, respiratory mucosa). But in WG kidney biopsy does not course with granulomas, so the glomerular injury is usually equal in both diseases. The three vasculitis (MPA, WG and CSS) course with constitutional symptoms and non-specific laboratory findings, such as increased HSS and C-reactive protein, anemia, leukocytosis, thrombocytosis, among other markers. However, a significant eosinophilia $\left(>1.000 / \mathrm{mm}^{3}\right)$ is found in CSS, and the biopsy may 
be suggestive of the disease. Additonally, in CSS the typical clinical profile is necrotizing vasculitis with eosinophilic granulomas in a patient with progressive asthma starting in adulthood, allergic rhinitis, nasal polyposis and cutaneous vasculitis ${ }^{(1-3,6)}$.

The basis for treatment of MPA is the use of corticosteroids, which is used for inducing remission and prophylaxis of recurrences of the disease. Aggressive schemes with prednisone and cyclophosphamide are often used. Some authors claim the use of pulse therapy with methylprednisolone in acute evolution. But plasmapheresis would be indicated in cases of a fast progressive glomerulonephritis with uremic syndrome and the need for dialysis. Another scheme would be to use only prednisone, which is usually reserved for limited forms of disease that do not compromise visceral organs ${ }^{(1-6)}$.

For the patient mentioned above, the treatment was introduced with pulse therapy of methylprednisolone associated to cyclophosphamide. At hospital discharge, the choice was a systemic immunosuppressant (azathioprine) and oral prednisone. One year after diagnosis, the patient is still taking systemic immunosuppressant and corticosteroid therapy without recurrences of the disease.

The treatment of arterial occlusive disease seeks to restore retinal circulation as quickly as possible through measures that include the sudden decompression of the eyeball and the use of fibrinolytic agents. Studies have shown that after 240 minutes of ischemia, the retinal tissue presents a massive and irreversible damage, so the early diagnosis and treatment is essential ${ }^{(7)}$. Once most cases of CRAO cause severe and irreversible vision loss, it is essential to determine the etiology of the disease, seeking to prevent the impairment of the contralateral eye $\mathrm{e}^{(7-10)}$.

\section{Conclusion}

The authors call attention to the association between occlusion of the central retinal artery and microscopic polyangiitis. Although many autoimmune diseases have been known as possible causes of retinal vascular occlusive diseases, this association has not yet been described in the literature. The serological analysis used in the search for systemic causes of occlusion of the central retinal artery usually includes examining the c-ANCA, which is requested in order to research a possible Wegner's granulomatosis. In addition to c-ANCA, pANCA should be requested, which is positive in most cases of MPA. The need for biopsy for diagnostic confirmation and treatment of systemic complications of this vasculitis with corticosteroids and/or immunosuppressants should be conducted by an enabled physician.

\section{RefERENCES}

1. Lauz S, Sonaglio A, Espíndola W, Facin E, Pintos V, Balaguez H. [Microscopic polyangiitis with encephalic and kidney manifestation. Case report]. Rev Bras Clin Med. 2010;8(5):464-6. Portuguese.

2. Hashimoto H. Microscopic polyangiitis in systemic sclerosis. Int $\mathbf{J}$ Rheumatol. 2010;2010:148528.

3. Gómez-Puerta JA, Bosch X. Anti-neutrophil cytoplasmic antibody pathogenesis in small-vessel vasculitis: an update. Am J Pathol. 2009;175(5):1790-8. Review.

4. Brandt HR, Arnone M, Valente NY, Sotto MN, Criado PR. [Medium and large vessel vasculitis]. An Bras Dermatol.2009;84(1):57 67. Portuguese.

5. Santos JW, Michel GT, Pereira CE, Capelozzi VL, Mileto JN, Fiorini CA. [Microscopic polyangiitis with alveolar hemorrhage] J Bras Pneumol. 2004;30(2):150-3. Portuguese.

6. Goldman L, Ausiello D. Cecil tratado de medicina interna. 23a ed. Rio de Janeiro: Elsevier; 2010.

7. Hofling-Lima AL, Moeller CT, Freitas D, Martins EN. Manual de condutas em oftalmologia. São Paulo: Atheneu; 2008.

8. Kanski JJ, Bowling B. Clinical ophthalmology: A systematic approach. 7aed. Edinburgh: Elsevier Saunders; 2011.

9. Ryan SJ. Retina. 5aed. St Louis: Mosby; 2006.

10. Biousse V, Calvetti O, Bruce BB, Newman NJ. Thrombolysis for central retinal artery occlusion. J Neuroophthalmol. 2007;27(3):215-30. Review.

\section{Corresponding author:}

Chrissiê Fianco Capitanio

Rua Cel. Pena de Moraes, 415 - ZIP Code: 242 -Farroupilha

(RS) - 95180-000 - Brazil

Email: chris@localnet.com.br 